\title{
UN VIAJE POR EL MITO DEL REY «CRUEL": LA LITERATURA Y LA HISTORIA DESPUÉS DEL ROMANTICISMO
}

\author{
ReBeCA SANMARTín Bastida \\ University of Manchester/ ILE \\ CSIC - Madrid
}

\begin{abstract}
I
Las relaciones entre los modos de escribir y entender la Historia y la Literatura han alcanzado un creciente interés en el marco interdisciplinar de las Humanidades, especialmente a partir.de la denuncia de la Historia como una práctica narrativa, siguiendo a teóricos como White (1992). Al mismo tiempo, una comprensión del fenómeno literario cada vez más contrastada con otras prácticas culturales ha continuado apuntando a la realidad histórica y su escritura como un interlocutor fundamental para entender la evolución de la Literatura, que sólo en el siglo XIX consolida de manera definitiva una legitimidad exclusivamente artística, en la concepción moderna del término ${ }^{1}$.

El propósito de este artículo es estudiar la relación que se establece entre la Historia y la Literatura durante la segunda mitad del siglo XIX a través de las narraciones que se escriben sobre el personaje de Pedro I el Cruel. El estudio de estos relatos ${ }^{2}$ contribuye a la comprensión de los mecanismos de construcción de esta última área; en un momento en que la actividad de los escritores se institucionaliza, es importante descubrir

\footnotetext{
${ }^{1}$ En el siglo XIX culmina un proceso que se había iniciado en el siglo XVIII: el término «Literatura» se aplica a partir de entonces a todo lo que antes se había denominado «Poesía». Lo que hoy entendemos como lo literario se aplicaba hasta el siglo XVIII a todo saber que se ponía por escrito. Agradezco al Dr. José Checa Beltrán el haberme llamado la atención sobre este aspecto.

${ }^{2}$ Aplico el término relatos o narraciones también a las relaciones historiográficas, siguiendo a $\mathrm{H}$. White en la comprensión de las mismas como artificios retóricos, que en el siglo XIX se aproximan a la composición de la novela. Véase, sobre todo esto y las diferentes consideraciones del relato histórico a lo largo de los tiempos, White (1992: 75-101).
}

Rlit, LXV, 129 (2003), 59-84 
cómo se define con respecto a otros sistemas con los que antes había estado estrechamente unida.

Para realizar este análisis, abordaré no sólo construcciones librescas sino también trabajos de las revistas ilustradas, pues éstas son en el XIX un magnífico termómetro de la producción cultural de aquellos momentos. Tras realizar una introducción general al ambiente de la época, donde estableceré las nuevas características que adquieren las dos disciplinas que abordo, mostraré ejemplos del tratamiento historiográfico de la figura de don Pedro, que me servirán de comparación con su presencia en la práctica literaria de la época. Destacaré entonces los ideales comunes de la Literatura y de la Historia, y las dificultades para llevarlos a cabo. En concreto, será el estudio del tratamiento temático o ideológico, más que las agrupaciones genéricas, el que me guíe para iluminar el debate entre la Literatura y la Historia después de ese momento de especial fusión (con el auge de la novela histórica) que se dio en el Romanticismo (Moreno Alonso, 1979). No hay que olvidar que en estos momentos todavía, como se refleja muy bien en la prensa de la época, la figura del escritor podía dedicarse con igual fundamento a la historia, el periodismo o la novela.

Escogeré para este análisis el personaje de don Pedro porque, en un siglo que volvió constantemente sus ojos a los siglos medios, se trataba de un modelo común para ambas actividades o disciplinas. El siglo XIX se especializó en la construcción de mitos medievalistas y a partir de la creación de este imaginario reveló sus fisuras y obsesiones, así como una vocación fundadora de recuerdos. No sólo el Romanticismo sino toda la época realista se dedicó a reinventar esta época, y a través de la recreación de determinadas temáticas, formas y personajes encontró los paradigmas que necesitaba para su definición. La tradición de don Pedro proporcionó, de esta manera, los materiales para la puesta en marcha de uno de estos procesos de articulación cultural.

II

El rey don Pedro, protagonista de la guerra fratricida de los Trastámara en el siglo XIV, se convirtió en todo un punto de mira en un momento en que se vivía un conflicto bélico parecido al de su época: la guerra carlista. La Literatura - especialmente algunos dramas- utilizó entonces la memoria del rey para explicar una situación política paralela; obligados los autores a elegir una versión de la Historia, las divisiones entre el apoyo o el rechazo hacia don Pedro se multiplicaron.

Éstas habían existido desde siempre. Desde que el rey murió asesinado a manos de don Enrique comenzó un viaje cronológico en el que los recuerdos se reinterpretaron en crónicas escritas pocos años después. En los 
relatos de Pero López de Ayala, Pedro de Aragón, Juan Froissart, Pedro Gómez Álvarez de Albornoz, Ben Jaldún, el despensor mayor de la reina doña Leonor, Berenguer de Puig Pardinas, Gutierre Diaz de Games o el obispo Rodrigo Sánchez ${ }^{3}$, don Pedro aparece una y otra vez durante la Edad Media como un fantasma obsesivo y difícil de interpretar. Se habló incluso de una crónica desaparecida atribuida a un tal Juan de Castro (en la que éste defendía y alababa al rey), cuyos rastros se perdían en una compleja intriga tejida de interpretaciones siempre diferentes.

Al final, la historia de don Pedro se transformó en una atractiva interpretación, y como tal la centuria decimonónica, tan propicia a recrear cuentos, se apoderó de ella con una pasión inusitada. Aunque los siglos XV, XVI, XVII y XVIII continuaron hablando de Pedro el Cruel, fue el XIX, especialmente en la segunda mitad de su existencia, el que con más empeño pensó a este rey. Sin duda porque los cuestionamientos que suscitaba debían ser resueltos.

Por ejemplo, en estos momentos la monarquía vive una importante crisis, no sólo por la venida de la Primera República sino también por una repetitiva guerra fratricida y una reina considerada por muchos impopular. Las Cortes, además, se veían obligadas a delimitar su poder ante el rey y miraban al pasado en busca de modelos fiables en unos días en que todavía se consideraba a la Historia como la magistra vitae de la época clásica. Pero, asimismo, otros motivos, mucho más sutiles, atraían la mirada del XIX hacia el rey apellidado el Cruel. Su figura tenía el privilegio de simbolizar valores en alza y otros prohibidos, relacionándose con conceptos de significado ambivalente en esta época, como la crueldad o la promiscuidad sexual (se extenderá por entonces el mito de sus mujeres), o también con el emergente credo socialista. Para algunos, don Pedro significará la opresión del pueblo castellano mientras que otros muchos le observarán como un rey que dio poder a la clase media frente a los nobles, que entabló alianzas e hizo caso de parias, judíos o árabes.

En cualquier caso, cada nuevo escritor que de él se ocupe lo reiventará a su manera en una labor narrativa en la que, curiosamente, participarán a partes iguales la Historia y la Literatura. Ambas emprenderán un viaje hacia el pasado donde, a través de la recuperación de papeles de archivos y de leyendas populares, la meta fundamental consistirá en desentrañar un carácter que se escapa a la delimitación. A la visión de don Pedro, como a la de la España medieval, le afectará profundamente los cambios que se producen en la mentalidad y la sociedad de los escritores ochocentistas, y por ello su figura se verá envuelta en turbulentas discusiones sobre el socialismo, la posición de la mujer o el papel de las clases

\footnotetext{
${ }^{3}$ Véase el recuento hecho, medio milenio después de la muerte de don Pedro, por Ferrer del Río (1851: 207-211) y Modesto Lafuente (1852: 309-312).
} 
medias ${ }^{4}$. Precisamente por su carácter de icono, las relaciones entre la Historia y la Literatura en la segunda mitad del siglo XIX adquieren una nueva la luz a través de la figura de don Pedro. La narración de sus desventuras mostrará de manera concreta cómo la Historia se vio influida por la Literatura, y la Literatura por la Historia, sin que muchas veces se estableciera una frontera concreta. Ambos terrenos delatarán las huellas de las corrientes científicas, estéticas y políticas vigentes, proyectando una imagen de don Pedro que responde y sugiere las necesidades más urgentes de la época posromántica.

En cuanto al aspecto científico, en la segunda mitad de la centuria decimonónica la ciencia se impuso con un novedoso afán de clasificación e imparcialidad que transmitió a la disciplina de la Historia. En su intento de ser narración imparcial de hechos verídicos, siguiendo los nuevos postulados de la escuela francesa ${ }^{5}$, ésta buscó entonces una atalaya desde donde contar los sucesos del pasado sin implicación, con asepsia, y teniendo siempre en cuenta su concepción evolutiva como progreso. Tras los descubrimientos de Darwin, la creencia en un futuro mejorado y positivo se fortaleció.

Una influencia parecida sufrió un género que el Realismo heredó de la corriente romántica: la novela histórica. Los autores de esta narrativa adoptaron una distancia emocional con respecto al objeto o tema abordado, desconocida por sus predecesores, y buscaron entre los archivos los datos más seguros para facilitar una narración impecable. Incluso llenaron de notas y de referencias a detalles, hechos y objetos del pasado momentos que antes se hubieran dejado sin explicación, abandonados a la imaginación del lector. La nueva novela «arqueológica» buscó demostrar, utópicamente, la veracidad del relato, al tiempo que la narración naturalista perseguirá su vocación científica.

Esta unión de propósitos no debería extrañar. Desde antes del Romanticismo Historia y Literatura caminan estrechamente unidas y en la primera mitad del siglo XIX muchos manuales de historia remedarán la ficción

\footnotetext{
${ }^{4}$ Sobre todos estos factores, que influyen en la imagen que del Medievo se tiene en la segunda mitad del siglo XIX, véase Sanmartín Bastida (2002).

${ }^{5}$ La historiografía filosófica del país vecino, a cargo de Guizot, Quinet o Tocqueville, intentará discernir las causas históricas de los hechos. Sus obras invitan al lector a reflexionar sobre el sentido de los acontecimientos, que tienen siempre una dirección. Los historiadores descubrían así unas leyes que desembocaban en la obtención de la libertad y cuya meta era el progreso, a partir de cuyas premisas se aplaude el reinado que favorece a las clases medias desde los postulados del liberalismo. Con la llegada del pensamiento positivista, se procura una distancia con la narración: para el historiador francés Fustel de Coulanges se trata de penetrar en el pasado que se quiere reproducir, de recoger el espíritu de una época. Pero la utopía objetivista no dejará de ser traicionada incluso por sus defensores, ya sean franceses o alemanes como Ranke, a través de la organización histórica y estética que establecen desde su atalaya.
} 
literaria. Por ello, con el Realismo la Literatura también se tomará en serio la imitación de la entonces llamada «ciencia» de la Historia, y escritores como Juan Valera argumentarán repetidas veces sobre la necesidad (y la dificultad) de que las novelas históricas se consideren o sean escritas con el rigor de un género académico ${ }^{6}$.

Pero no sólo la asepsia científica o el «evolucionismo» afectarán a las narraciones históricas o literarias. También la nueva preocupación por la clase media (fruto de la mentalidad burguesa después de 1789) y por el pueblo llano o clase baja (consecuencia de un pujante socialismo) influirán en las miras de estos dos géneros de escritura, que comienzan a interesarse más por la vida cotidiana que por los grandes acontecimientos bélicos. En esta ocasión, el ejemplo más radical será el del inglés William Morris, que además incluye el fin doctrinal o moralizador en su vocación histórica y literaria (Boos, 1992: 3-37). Éste elemento, como veremos en seguida, será en España también prácticamente inseparable de la narración de historia o de la literatura de estética realista.

De hecho, novelas, manuales y artículos que estudian el pasado en las revistas ilustradas demuestran que la distancia entre estos modos de escritura no era grande. Una indiferenciación de tareas calibrable también por esa condición conjunta de periodista, novelista o historiador esgrimida por muchos profesionales de las letras en la prensa periódica.

Don Pedro es entonces el catalizador de una energía común, que demuestra con su presencia las contradicciones y confusiones en que caían las diferentes categorías de discursos. Quizás este personaje ofrece una atracción demasiado poderosa como para atenerse a unas reglas o intenciones fijas. El monarca, «cruel» o «justiciero», se convierte en el gran desenmascarador de los propósitos (¿imitados?, ¿descubiertos?) de la ciencia histórica y de la ficción literaria, de la falta de asimilación de esos postulados que defendían las palabras meditadas de los escritores. Don Pedro protagoniza entonces uno de los largos viajes con los que la utopía ochocentista descubre una nueva frustración de sus sueños, y así, contando la vida de un personaje, una centuria que cree en la ilimitada capacidad del progreso no deja de encontrar las propias limitaciones.

${ }^{6}$ En numerosas ocasiones se pronunció Valera sobre las exigencias de la novela histórica, debatiendo su sentido en la narrativa actual. Véase Valera, (1905, t. II: 105; 1913, Correspondencia: 148). Este escritor valora las lecciones de historia que se encuentran en las novelas de época (1912, t. XXXI: 201), pero expresa la dificultad que exige su escritura por la cantidad de erudición y preparación exigidas $(1908, \mathrm{t}$. XV: 38 1909, t. XXI: 184), en la línea de lo que hemos afirmado. Por ello, cuando Valera se plantea el inevitable anacronismo que se deriva de la escritura de la novela histórica, debido a que el novelista no vive en el pasado que relata (1909, t. XXI: 33), acaba renegando de la utopía del Realismo: una «estricta» novela histórica, que pretenda contar los hechos con nimia escrupulosidad, es prácticamente imposible (ibidem: 35). 
En cuanto a la Historia, muchos fueron los relatos que se escribieron sobre Pedro $\mathrm{I}^{7}$, utilizando una serie de justificaciones que implícitamente se daban por aceptadas en el lector y que encontraremos también en obras literarias, como los valores de imparcialidad, patriotismo, progreso, ciencia o verdad. A medida que se escriben nuevas narraciones sobre el rey, los compositores recordarán a los que les anteceden y se añadirán en forma de un «puesto» en una determinada serie (la de los defensores o la de los atacantes del rey) que se remonta a la Edad Media, de modo que se textualizan a sí mismos en una cadena productora de representaciones ${ }^{8}$.

Tras la historia del P. Mariana del siglo XVII, algunos hablarán del monarca como un ejemplo negativo de lo que no debió ser, un rey demasiado cruel y vengativo que acabó deslegitimando con su comportamiento su propia causa. En esta línea, Antonio Ferrer del Río escribirá en 1851 una memoria premiada por la Academia de la Historia en la que, desde una pretendida imparcialidad, defiende la culpabilidad de don Pedro en los sucesos que se le imputan. Sin duda el trabajo de Ferrer dejará una gran huella en los escritores de historia de España considerados liberales, como Modesto Lafuente o Eduardo Zamora y Caballero. Estos narradores sostendrán la culpa de don Pedro y su merecido y terrible destino final, dentro del juicio a personajes históricos que la Historia del XIX se consideraba «obligada» a realizar.

Si para argumentar esta teoría el principal punto de apoyo era la crónica de don Pedro que años después de su muerte había escrito Pero López de Ayala (en la primera de sus Crónicas de los Reyes de Castilla), este texto será atacado por aquéllos que reivindiquen la memoria del rey. Con este objeto se pondrá en cuestión su imparcialidad, uno de los valores más importantes para el historiador contemporáneo. Así se posicionan José Montoto (1847), Joaquín Guichot (1878) o Francisco de Tubino (1887) ${ }^{9}$.

Otro de los argumentos que servirán para defender una u otra postura de los historiadores será apelar al patriotismo del lector para que éste se

\footnotetext{
7 Para un recuento de los historiadores que criticaron o vindicaron al monarca, véase Cirujano Marín et alii (1985: 108-109).

8 Casi todas las narraciones históricas sobre el rey cuentan al final de las mismas con una relación de los que defienden y los que atacan a don Pedro.

9 Montoto (1847: $\mathrm{x}$ ) opina que al cronista hubo de influirle el estar bajo el servicio de don Enrique, pues era necesaria una justificación de las traiciones del Trastámara. Guichot (1878: 48), en su historia, asegura que no seguirá a Ayala, porque sabe que don Enrique hizo destruir los documentos del rey muerto que podían delatar que no era tan cruel. Tubino (1887: 99), por su parte, se opone a los historiadores «que dan la razón a la Crónica de López de Ayala y se la niegan al hijo y sucesor del que venció en el Salado y Algeciras y legisló en Alcalá de Henares».
} 
comprometa a aceptar la versión propuesta. Los hechos son interpretados así desde diversas ópticas, y la cuestión de la unificación de España o del comportamiento de don Pedro con los árabes se tratará de forma controvertida y anacrónica. Si para Ferrer del Río el monarca no debió atacar Aragón sino Granada, Guichot considera esto una muestra de patriotismo y de una voluntad adelantada de expandir Castilla. Por su parte, Tubino descubre en el rey la personificación de una Castilla guerrera, y convierte este argumento en una cuestión nacionalista ${ }^{10}$.

Castilla se transforma así, dentro de la historiografía de la época, en el eje vertebrador de las virtudes de los españoles; virtudes más que vicios, ya que la nueva historiografía, llevada por el ejemplo de escritores como el francés Mérimée y su historia sobre don Pedro, intenta contextualizar los hechos en su época y disculpar las crueldades cometidas, al tener en cuenta el momento en que suceden (Guichot, 1878: 7) ${ }^{11}$.

Otro argumento muy manejado en estas narraciones será el concepto de progreso, esgrimido fundamentalmente a la hora de dilucidar si el reinado de don Pedro constituyó o no un adelanto para España. Lo que queda claro de este nuevo «juicio» es la ideología política de la que parte cada narrador. Ferrer del Río, desde su pensamiento liberal, ensalza el papel de lo que él califica estado llano, frente al poder amenazante de la aristocracia o el clero. Mérimée (1865: 6), a partir de otro punto de vista, celebra que el rey don Pedro dé un mazazo a la anarquía feudal, haciendo avanzar la civilización. El debate social continúa en la prensa ilustrada y para Jove y Luna (1869) o Fuensanta del Valle (1874) el monarca se convierte en símbolo de igualdad por sus leyes contra la nobleza; idea que también recogerá Guichot, quien intenta ganar para su causa al movimiento social progresista, dibujando a Enrique de Trastámara como un usurpador que fomenta el feudalismo. La defensa del monarca se apropiará así del discurso social en un momento en que se extiende el socialismo, y para rechazar las acusaciones de tirano que dirigía a don Pedro la izquierda progresista (por ejemplo, Zamora y Caballero [1873: 572] le califica de «fiera coronada»).

${ }^{10}$ Tubino (1887: 58) ve en don Pedro al «valeroso príncipe, que si pudo cometer -y cometió- actos a todas luces censurables, también brilló por prendas que todo ánimo esforzado y viril temperamento, han de admirar, viendo en D. Pedro la personificación del caballero castellano, con las calidades y flaquezas que en los siglos medios hubieron de distinguirle».

11 «Ajourd'hui nous avons à tenir compte des mœurs de son temps et des difficultés qu'il rencontra» (Mérimée, 1865: 6), pues «Sa dissimulation, ses parjures, sont les vices de son époque» (ibidem: 534). Mérimée busca un férreo sentido de imparcialidad en medio de su discusión sobre los crímenes del monarca, como muy bien advierte Dakyns (1973: 91). Su obra, publicada primero en la Revue des Deux Mondes en 1847-1848, y luego como libro en 1848 (Fairlie, 1947: 316), no debió de ser muy leída en España, a juzgar por la escasa referencia que a él hacen nuestros historiadores. 
Entre todos estos argumentos, una vez más el prestigio de la ciencia servirá para justificar a unos y a otros. Es un momento en que se rechaza «la autoridad», aunque los antecedentes historiográficos que el historiador esgrime como de su «bando» otorguen el mismo prestigio que los archivos descubiertos. También es éste un período en el que la Historia intenta purificarse de los abusos de ficción que cometió anteriormente, por lo que el argumento del «grupo» contrario será tachado siempre de leyenda. La narración muestra ahora como su principal valedero la reproducción de documentos en abundantes apéndices. Casi todas las historias contarán con estos añadidos $\mathrm{y}$, además, en la prensa ilustrada se publica mucha documentación inédita que será interpretada en favor de una u otra postura, como vemos en los ejemplos de Fernández Espino (1860) o Ramírez de Arellano (1860), que usan el epistolario medieval ${ }^{12}$.

Asuntos candentes en el momento, como la nueva situación social de la mujer, se verán mezclados en esta contienda de la Historia. Y en este caso los silencios textuales, la no mención de la información que venía de López de Ayala, revela más que las mismas palabras. Si la presencia de María de Padilla en la vida de don Pedro es callada por Guichot, lo mismo hace Tubino con doña Blanca de Borbón. Ambas mujeres pueden convertirse en un estorbo para una representación positiva del protagonista, por lo que su comportamiento se debate con el objeto de fijar una visión concreta del monarca. Mientras que Ferrer del Río defiende a doña Blanca, aplaudiendo su deseo de refugiarse en Toledo y la simpatía que despierta en sus vasallos por los actos poco caballerosos de don Pedro, Guichot critica que la reina se rebele contra su marido con alevosía ${ }^{13}$. En este sentido, el uso de un vocabulario para calibrar un hecho u otro obliga al lector a alinearse con el autor de la narración.

En general, lo que se juega en estas diferentes versiones es la búsqueda de la verdad, y ésta es importante en la medida en que todavía la Historia se considera maestra de la vida. Pero de la «absolución» o no de don Pedro (y uso este término porque todas las historias se ven impelidas a establecer un juicio) dependerán los posicionamientos políticos a favor de la monarquía o de unas determinadas clases sociales.

Muchos de los que rescataban a Pedro I como justiciero sostenían que la historiografía precedente había utilizado las fuentes sin rigor. Según algunos, el hermano bastardo, como se califica a Enrique de Trastámara, había falsificado los datos que hubieran podido comprometer su legitimidad. Se daba por inauténtica así la versión de López de Ayala que repro-

\footnotetext{
${ }^{12}$ Véase la documentación presentada en estos trabajos, donde se debate en torno a la actuación del rey don Pedro en Aguilar.

${ }_{13}$ Guichot (1878: 242) advierte que no es igual el adulterio de la reina con Fadrique que el que cometió su esposo, pues dentro de las costumbres de entonces la mujer vivía en condición inferior al hombre y debía sufrir sin protestar los devaneos de su marido.
} 
ducía la historia del P. Mariana, y se reivindicaba a Pedro I por el significado político de sus actuaciones. Desde el punto de vista de algún demócrata, el drama de Pedro el Cruel radicó en que quiso ser rey de todos anticipándose al elegir la igualdad como valor supremo ${ }^{14}$. La opción ideológica limitaba las visiones escogidas, de modo que hasta los eruditos que usaban las fuentes como argumentos de autoridad contribuyeron a que la polémica se ciñera a los límites de la interpretación política.

Un ejemplo de hasta qué punto se trataba de concepciones ideológicamente matizadas nos lo dan unas abundantes muestras de chauvinismo en las que la actuación del famoso Bertran du Guesclin sale mal parada. En esto coinciden todos los cronistas del rey: don Pedro murió dignamente asesinado de una manera un tanto cobarde por un militar francés. La divergencia de opiniones se establecerá en torno a si el personaje lo merecía o no. Para dilucidarlo, se esgrimirá a menudo el parecer del pueblo, que en la nueva corriente historiográfica se' convierte en el verdadero juez de la Historia; y a éste se le podrá considerar diversamente alegre o triste tras la muerte del monarca ${ }^{15}$.

Pero si de estas narraciones depende el ideal político, no menos influye la concepción de la Historia: seguidora de la ciencia, imparcial, fiel a los hechos: Guichot (1878: 8) asegura que es la «ciencia de las ciencias» y Tubino (1887: 2) habla del «decoro de la crítica histórica», denunciando «la inopia de nuestra atonía cientifico-filosófica». Sin embargo, en la realización de este propósito las contradicciones en que caen sus compositores llaman profundamente la atención. La asepsia se traiciona en el tono apasionado con que se defienden las posturas: en numerosas ocasiones utilizando insultos contra los personajes contrarios a las simpatías del escritor ${ }^{16}$. Por otro lado, se hará caso de la rechazada «leyenda» si interesa en

${ }^{14}$ Para un examen más completo de las diferentes posturas que historiadores liberales, tradicionalistas y federalistas de la época isabelina toman con respecto a don Pedro, véase Cirujano Marín et alii (1985: 107-112). La lucha entre dos poderes feudales (la Corona y la aristocracia) se transformó en una batalla entre la igualdad y el privilegio en las páginas de estos historiadores liberales y demócratas.

${ }^{15}$ Según Ferrer del Río (1851: 199), «Castilla, la nación más leal a sus reyes, la menos propensa a alborotarse, aplaudió su trágico fin con aclamaciones sinceras» (199; la cursiva es del texto). Guichot, por el contrario, afirma que su muerte no alegra a los castellanos, pues de ser así no tendría sentido que se mostrara por las ciudades la cabeza del monarca para que éstos se convencieran de que había muerto y depusieran su rebeldía. Si los ciudadanos no se revolvieron contra él fue porque no era tan malo.

16 Véanse comentarios como los de Guichot (1878: 15): «iQué grande debió ser el hombre que hizo doblar la rodilla ante su cadáver al mismo que le asesinó alevosamente!»; Tubino (1887: viii): «Entiendo que no habrá lector que no se regocije, viendo justificada la ejecución del traidor hermano, que tan inicuamente se conducía, pagando beneficios con deslealtades y traiciones». Por su parte, Ferrer del Río (1851: 52), aunque asegure que procura inquirir la verdad y que sería «mengua» que «la pasión guíe» su pluma, comenta: «Erízase el cabello, se revuelve la sangre y tiembla la mano al es- 
los derroteros del relato ${ }^{17}$. Esto lleva a que, cuando desde la postura revisionista de la Historia se releen en la prensa una serie de asuntos de la leyenda de don Pedro (como la disecación del judío o la muerte de Fernández Coronel), se desenmascara el supuesto error en narraciones con estructura de ficción, que demuestran que a las actuaciones del monarca se les dio una intención «torcida». En este caso, la ficción literaria, en forma de cuento, corrige a la Historia, y es éste un ejemplo más de esa correlación entre Literatura e Historia que desde el comienzo se plantea en la narración ochocentista sobre nuestro rey.

\title{
IV
}

En la Literatura, el motivo de don Pedro será un verdadero filón de relatos, tanto para las tablas como para la novela o los versos. Lo expresó muy bien Fernández y González (1930: 38) en El condestable don Álvaro de Luna, en 1851:

\begin{abstract}
¿Necesita un zurcidor de dramas, un personaje tremendo, feroz, entregado a instintos brutales? Ahí está el rey don Pedro. ¿Se quiere para una leyenda tenebrosa una especie de ogro, de vampiro, de tigre humano? Siempre el rey don Pedro. ¿Se desea interesar al público con las desgracias y con el heroísmo salvaje de una mujer? Se apela a doña Blanca de Francia o a doña María Coronel.
\end{abstract}

Fernández y González se quejará entonces de que: «El público, engañado por [...] los que llenan [...] de abortos los libros y la escena, se indigna contra la memoria de aquel rey, le desconoce y le odia». Por ello, desde una postura bastante parecida a la de la historiografía, los escritores que simpatizan con el monarca tratarán de comprenderlo y dirán que sus actuaciones crueles se interpretaron de manera injusta. Así lo dejará claro Zorrilla (1905: 297) en una muy famosa escena de El zapatero y el rey ${ }^{18}$ :

Por odio y contrario afán calumniado torpemente,

tampar la relación de tamañas atrocidades [...]; pero a vueltas de la indignación que excitan en toda alma noble, se envanece el historiador pregonando la heroica lealtad [...] de la nación castellana» (ibidem: 121-122).

17 Así, Guichot echará mano del romance para defender la existencia de relaciones entre Fadrique y la reina doña Blanca, pese a su rechazo de la leyenda popular contra don Pedro. Tubino, por su parte, considerará leyenda la historia de María Coronel, y Lafuente, la versión que defiende a don Pedro.

${ }_{18}$ El zapatero y el rey (Zorrilla, 1905: 295-430) se estrena entre 1840 (la primera parte) y 1842 (la segunda), y se publica en 1840 y1841, respectivamente. La segunda estrofa que reproduzco en la cita siguiente debió de hacerse bastante famosa; véase Palacio (1888), donde tiene una puntuación distinta. 


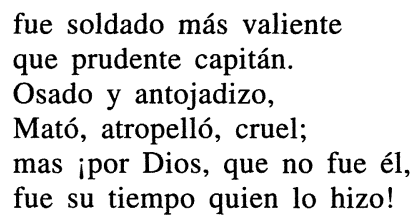

Para su visión de don Pedro, el siglo XIX no partió de la nada, sino que se encontró con un tratamiento literario de larga tradición. Lope de Vega había hecho participar a este personaje en siete de sus comedias, de las cuales en las propiamente históricas se caracterizaba por su ambición, soberbia y celo justiciero, mientras que en las amorosas se constituía simplemente en un personaje «galán», con alguna que otra huella de su antiguo carácter ${ }^{19}$. Esta imagen la recogerá Fernández y González, que presentará a un don Pedro bravucón, sangriento y efusivo en amores en su Men Rodríguez de Sanabria, obra de 1853. Desde los dramas de Lope, la figura del Rey «Cruel» se hará sumamente popular, especialmente por su talante justiciero con nobles altaneros y por su respeto a los concejos castellanos. Otro motivo de su atractivo provenía del «anticlericalismo» del rey, pues era muy conocida la fábula del zapatero y el prebendado que dramatizó Zorrilla. Asimismo, su «activa» faceta amorosa atraía a los escritores de la época ${ }^{20}$.

Zorrilla fue de los que supo combinar mejor la semilla de Lope con el espíritu de los nuevos tiempos. Su definición del monarca en la obra mencionada es magistral y valdría por muchas páginas de explicaciones. Don Pedro fue cruel, sí, pero sus caprichos son perdonables por tratarse de lejanas épocas con diferentes costumbres; en la Edad Media se pueden permitir otras cosas que ahora no (recuérdense los argumentos de Mérimée). Pero además se trata de la repetida valoración del castellano audaz, que no piensa dos veces sus actos porque es fogoso, atrevido, con un alto sentido de su persona ${ }^{21}$. Y tanto valdrán estas características para don Pedro como para el Cid, en los versos mencionados que pronto se hicieron populares, lo que demuestra que existía una necesidad social de estos iconos

19 Sobre la imagen de don Pedro en el Siglo de Oro puede consultarse el libro de Sánchez (1994) y el recuento que a finales del siglo XIX realiza Lomba y Pedraja (1899: 257-264) de las comedias áureas sobre don Pedro.

${ }^{20}$ Algo interesante si tenemos en cuenta que los personajes históricos del pasado elegidos en la poesía española de la segunda mitad de siglo guardan más relación con los conflictos políticos y menos con las historias de amor, de modo que los romances amorosos de don Pedro o don Rodrigo son más bien excepciones.

${ }^{21}$ En El zapatero y el rey el autor nos representa a don Pedro como un joven arrebatado y justiciero, que se alude a sí mismo de manera presuntuosa en tercera persona (con él debe tener cuidado Mahomad, el rey Bermejo) y que produce la desconfianza de Aldonza por sus impulsos crueles: «Estemos muy sobre aviso,/ que tiene más de león,/ cuya sangrienta afición/ saciar antes es preciso» (Zorrilla, 1905: 320). 
históricos. Sea como sea, para Zorrilla el Rey «Cruel», a quien dedicó también romances, será uno de sus personajes favoritos ${ }^{22}$.

Este poeta muestra además cómo en la Literatura, al igual que en la Historia, el chauvinismo hace su aparición. En su obra, «Beltrán de Claquín» (que así es como llaman entonces muchos a Du Guesclin) no disfruta de un benévolo retrato, con un espíritu de mercenario que contrasta con el idealismo español. Frente a este personaje de inferior talla moral, don Pedro se mostrará como un orgulloso castellano, que no quiere pedir ayuda a los franceses para salir de su emboscada. Al contrario que este monarca, Enrique de Trastámara, como en la composición poética de Hartzenbusch (1850), es pintado con caracteres negativos, y recibirá un castigo por el asesinato de su hermano cuando el protagonista de la obra, el ZapateroCapitán, haga matar a su hija Inés ${ }^{23}$.

La Edad Media nacionalista y romántica y esta figura de don Pedro tendrán su descendencia en la segunda mitad de siglo, especialmente en las tablas. A raíz de la Restauración, don Pedro se hizo una figura muy socorrida, con una imagen frecuentemente positiva ${ }^{24}$. Pese a la pintura negativa de López de Ayala y del Romancero, el resurgimiento de los ideales monárquicos se aprecia en el tratamiento del rey, que se muestra justiciero y galán, recogiendo la herencia áurea más que la ambivalencia de Zorrilla o la historia de López de Ayala. De todos modos, muchas veces el reinado de don Pedro servirá sólo como telón de fondo del drama, y además hubo también creaciones teatrales que no se mostraron tan benevolentes con el monarca. Así, en María Coronel, de Retes y Echevarría (1872), el Rey «Cruel» no sale muy bien parado, pues los autores siguen la tradición más desfavorable, aunque no carguen en exceso las tintas ${ }^{25}$.

$\mathrm{Y}$ es que en esta segunda mitad del XIX español, cuando hasta la ópera se ocupa de nuestro personaje (ahí está Eslava con su Don Pedro el Cruel),

\footnotetext{
${ }^{22}$ Cabe destacar, de entre los compuestos por Zorrilla, dos romances, aunque fueron escritos en la primera mitad de siglo: Una aventura de 1360 y Justicias del Rey D. Pedro (Zorrilla, 1917: 317-321; 327-332). En esta misma época, en torno a la figura de don Enrique, escribe Hartzenbusch (1850) su poema Isabel y Gonzalo, en el que la protagonista, al no poder amar a Gonzalo por impedimento de su padre Enrique de Trastámara (nada menos), se mete a monja.

${ }^{23}$ La misma visión, chauvinista y con castigo divino, la encontramos en otro poema suyo: Los borceguíes de Enrique II (Zorrilla, 1917: 303-311), cuando se refiere a la muerte del rey «a manos de una traición/ de serviles extranjeros» (ibidem: 303). En el poema, muere Enrique II de dolencia incógnita, como si se tratase de un castigo de Dios.

${ }^{24}$ De hecho, de los cinco dramas que Cabrales Arteaga estudia sobre el monarca, cuatro ofrecen una positiva imagen del mismo, como rey justiciero y galán, además de «imparcial» (Cabrales Arteaga, 1986: 49; 1985: 301 \& 307).

${ }^{25}$ Esta obra, la historia de otra mujer víctima de los amores del rey don Pedro (que prefirió el martirio a entregarse al rey), consiguió un gran éxito en el teatro, como deducimos de la crítica de Nombela, quien da por supuesto en el lector el conocimiento de estas leyendas medievales (Nombela, 1872: 291).
} 
el aprecio hacia el rey sufre constantes vaivenes, por lo que será una figura recurrentemente debatida. No sólo Zorrilla, en poesía, y Fernández y González, en novela, se ocupan, como hemos visto, de él: el Duque de Rivas se había referido a don Pedro en sus romances históricos de 1841 con una actitud ambigua que heredarán los sucesores ${ }^{26}$. En este sentido, en función de contrapuestas ideologías, la Literatura tampoco se ponía de acuerdo sobre el juicio del monarca. Así, tras el drama Blanca de Borbón de Espronceda (editado póstumamente por su hija Blanca en 1870), de planteamiento antimonárquico ${ }^{27}$, podemos encontrarnos al republicano Castelar mostrando una visión negativa del rey en su novela El suspiro del moro, pues lo considera como un «verdadero revolucionario de su tiempo» que quería el predominio del poder monárquico sobre los otros ${ }^{28}$, o a escritores de dramas plantear esta época en paralelo a la de la guerra carlista ${ }^{29}$.

En estas décadas, la Literatura no dejará, pues, de sentir el peso de las simpatías políticas, aunque la distancia entre creación de ficción e historia empiece a ser problemática y debatida. Ahora las composiciones poemáticas reivindican personajes como Enrique de Villena o don Pedro, y revisan,

26 Véase Saavedra (1841: 31-96). En estos romances la «crueldad» de don Pedro se reconoce, pero se presenta de manera más bien idealizada. Como ya observó entonces un contemporáneo suyo, Vidart (1890: 18): «Es de notar que el Duque, sin alardear de erudito, pero guiado por su agudo ingenio y su honrada conciencia, no falsificó la historia para pintarnos al cruel rey Pedro I de Castilla como un dechado de caballeros».

27 Véanse los versos en contra del Rey don Pedro, «Rey de Castilla», en Espronceda (1954: 268), donde se nos pinta a un monarca despreocupado y entregado al placer de las fiestas. En este texto, don Enrique tiene connotaciones claramente positivas, en su contraposición al «tirano».

28 «D. Pedro el Cruel no se curó sino de combatir con la nobleza capitaneada por sus hermanos los infantes de Trastámara, ensangrentando, más que fortaleciendo, el principio monárquico, en su durísimo reinado de verdadero terror» (Castelar, 1885: 7). La cita del texto está en la página 68.

29 Sobre el drama medievalista y su implicación política con el carlismo, véase Cabrales Arteaga (1985: 309-312). En esta línea de interpretación política, pero desde el género de la conferencia, Cánovas confía en la versión de López de Ayala para plantear un paralelismo entre la guerra civil del siglo XIV y las carlistas, según deducimos de su texto Intervenciones extranjeras en Castilla durante el reinado de Don Pedro I, que se comenta en B. (1889). Al parecer, Cánovas denunciaba que las muertes causadas por don Pedro perjudicaban al Bastardo. Esta fidelidad a la versión de López de Ayala se puede colegir también de una referencia de Valera en su estudio sobre el Duque de Rivas (Valera, 1911, t. XXVII: 71-196): critica el escritor a los que ensalzan a figuras históricas como Pedro I, de quien Cánovas demostró que no era muy fiable. Finalmente, Juan Antonio Cánovas del Castillo nos informa en su estudio preliminar a la obra de Cánovas de la desaparición de su conferencia Don Pedro I el Cruel de Castilla, en la que al parecer hablaba de las contiendas dinásticas del pasado, estableciendo un paralelismo con las guerras carlistas (sus consideraciones iban desde los Trastámara a la Beltraneja, y desde la Guerra de Sucesión al carlismo); también desaparecida, La guerra fratricida de los Trastámara debatía, asimismo, la cuestión dinástica de su tiempo (Cánovas del Castillo, 1981: 30). 
de manera respectiva, sus malas famas de hechicero y cruel. Así, el historiador José Amador de los Ríos hizo una primera versión de su romance Abú Said en Sevilla en 1839, basada en la historia de Mariana, en la que se nos presenta al Rey «Cruel» matando de una lanzada al moro al que traiciona, después de escarnecerlo. Pero cuando cuarenta años después editó su obra poética, cambia su poesía inspirada por la leyenda de el Cruel en una composición laudatoria de el Justiciero $^{30}$. En plena corriente apologista de don Pedro, Amador de los Ríos hace suavizar en sus versos la actitud del rey. A pesar de este cambio, comentando sus poemas, Juan Valera (1910: 101-102) le advertirá que en la poesía es más efectivo idealizar a don Pedro, aunque éste deba ser condenado. Incluso echará en cara a Amador de los Ríos el ser demasiado racional en su representación última de don Pedro, y no actuar como un poeta, idealizando al monarca, que es «la glorificación del tirano, valiente, nivelador, que entusiasma al pueblo, y cuyas atrocidades pasan por sapientísima justicia». Para Valera, el historiador debió dejarse llevar por la opinión popular y encomiar a don Pedro sin restricciones, como Zorrilla.

El ejemplo de Amador de los Ríos nos muestra cómo la ocupación en la poesía del escritor de Historia tiene consecuencias sobre el retrato del rey. Otra muestra es la de Ramírez de Arellano (1860a, 1860b), que publica un documento en la Revista de Ciencias, Literatura y Artes sobre la toma del castillo de Aguilar y luego compone un poema en torno al mismo asunto en el que la actuación de don Pedro es criticada. La poesía en estos casos va a la zaga de la Historia o de las investigaciones de archivo.

Muy alejadas de este historicismo se presentan, sin embargo, las leyendas de Cano y Cueto, una de las cuales se ocupa de la de María Coronel, poniendo un gran acento melodramático ${ }^{31}$. O la presentación que del monarca realiza Ramón de Campoamor, quien en su poema Colón critica las obras del rey «desnudas de piedad», en su línea de hacer consideraciones morales sobre la Historia (Campoamor, 1853: 93).

Pero el interés que despierta en el siglo XIX español esta figura se extiende también hacia los países vecinos, tanto en la prosa histórica como

\footnotetext{
${ }^{30}$ Modifica entonces el romance, de modo que don Pedro ahora vacila antes de hacer justicia y la responsabilidad de la sentencia la comparte con el Consejo. El rey moro muere al resistirse a los caballeros que iban a prenderle. Aquí Amador pudo sentir la presión de las obras defensoras de don Pedro, y éste puede ser un ejemplo de la influencia de la producción historiográfica sobre la poética. Para Carrasco Urgoiti (1956: 405-406), la narración poética, muy coherente en la primera versión, se hace difusa y contradictoria en la segunda.

${ }^{31}$ En la escena final, don Pedro, con «la sangrienta boca ensangrentada», rasga el cuello de María Coronel (Cano y Cueto, 1875: 115), a quien llama el poeta tórtola viu$d a$, la cual, inverosímilmente, se quema en un instante la cara. Recordemos que este episodio no aparecía tal cual en la obra de López de Ayala: la resistencia con fuego de la Coronel fue descrita por primera vez en Las Trescientas de Juan de Mena.
} 
en la ficción: en 1848, Mérimée presentó la historia de don Pedro que hemos mencionado; en 1854, Alejandro Dumas escribe Le Bâtard de Mauléon, en la que narra las aventuras de un joven héroe francés en la Corte del monarca ${ }^{32}$; en 1855 , la inglesa Charlotte Yonge saca a la luz The Lances of Lynwood, donde don Pedro es protagonista de una novela de aventuras ${ }^{33}$; y, en la década de los 80 , Leconte de Lisle publica sus poemas sobre el rey, que resaltan su lado más feroz y bárbaro ${ }^{34}$. Estos versos fueron publicados en los Poèmes tragiques, y en ellos Leconte hace del rey una pintura más negativa que la de Mérimée ${ }^{35}$, sin consultar seguramente a López de Ayala y sí los romances sobre este personaje, que solían serle hostiles. Leconte de Lisle, que recrea sus historias con atención arqueológica, se deleita en la escena en que don Pedro se ríe mientras come con María de Padilla, cuando su perro aparece con la cabeza de su hermano don Fadrique en la boca ${ }^{36}$. Su recreación en la barbarie del Medievo dejará un influjo en poetas españoles como Núñez de Arce, quien había manejado parte de su obra (como refleja en su discurso sobre la poesía de 1887 leído en el Ateneo), según se aprecia en las composiciones Hernán el Lobo y El vértigo. Estos versos delatan una estética cercana a la de Leconte, con animalizaciones y preferencia por el terror gótico.

Si nos centramos ahora en la prensa española, vemos cómo artículos híbridos entre la escritura de Historia y de ficción (de acuerdo con la fusión del discurso histórico y literario aún vigente) disputan también sobre la figura del rey. El escritor de cuentos Antonio de Trueba (1863) escribe una muy interesante historia en la que relata la muerte de don Juan, que pretendía ser señor de Vizcaya, a manos del rey don Pedro. El autor, al pretender mostrarse imparcial con la figura del monarca, nos dejar entrever las grandes discusiones de la época sobre la moralidad del Rey «Cruel»:

\footnotetext{
${ }^{32}$ Allí sucede la muerte de don Fadrique; por lo que sabemos, el autor conocía al menos el romancero de don Pedro (Fairlie, 1947: 318-321).

${ }^{33}$ La novela se centra en la alianza entre el Black Prince of Spain (Edward, el príncipe de Gales) con el rey don Pedro para vencer a don Enrique. Véase la bibliografía medievalista que incluye Boos (1992).

${ }^{34}$ Como era de esperar, tras haber leído seguramente la novela de Dumas y la obra de Mérimée. Para un análisis completo de los poemas de Leconte de Lisle, véase Fairlie (1947: 315-341).

${ }^{35}$ Mientras Mérimée duda del asesinato de doña Blanca y sugiere que su muerte fue natural (pues nada de interés podía sacar don Pedro con matarla, si ya estaba encerrada), Leconte da por sentado que el crimen fue obra del monarca.

${ }^{36}$ Este episodio no aparece en López de Ayala (1953: 482), quien simplemente dice que el Rey come «donde el Maestre yacía muerto en una quadra que dicen de los Azulejos, que es en el Alcázar». Leconte de Lisle sitúa el episodio de don Simuel antes del de don Fadrique, dejando el de doña Blanca para el final, tal vez con el objeto de presentar un crescendo de terror, aunque no fue ése el orden de composición. El francés muestra las supersticiones que considera características de la historia española medieval, resaltando los aspectos más negativos, como la falsedad y la hipocresía.
} 
Trueba piensa que «no se ha escaseado medio alguno, por odioso que fuese, para pintar al desgraciado Don Pedro como un monstruo de falsía y crueldad...», ni escritores que lo traten «calumniosamente». Y en esto destaca a López de Ayala como el que más ha contribuido a hacer odiosa la memoria de don Pedro, empeñándose en pintarlo sanguinario en extremo. Pero aclara, por si el lector pudiera sacar una impresión equivocada, que tampoco es del otro bando, en el que incluye por igual nombres de historiadores y literatos que se constituyen, según él, en ciegos admiradores del rey. Y es que, ya que la derecha política, a través de personajes como Antonio Nocedal ${ }^{37}$, se había apropiado de la defensa del monarca, Trueba se ve obligado a justificar el no ser demasiado duro con este personaje ${ }^{38}$. El mismo tipo de polémica que refleja Vallejo (1886) en su historia Ruzafa, aunque éste muestra claramente su parcialidad hacia el rey cuando achaca a Enrique de Trastámara la propaganda negativa que don Pedro sufrió ${ }^{39}$.

Menos interesados en la visión política, otros relatos de estas revistas, de carácter más definidamente literario, se complacen puramente en una recreación estética en la crueldad de Pedro I, muy en la línea de la poesía de Leconte. Éste es el caso de Márquez (1887), que pinta la muerte de doña Blanca y de don Fadrique con un especial deleite en la descripción de la sangría ${ }^{40}$. Se trata de un ambiente tétrico y salvaje que repite la tradición de parnasianos y republicanos franceses como Michelet, quienes rechazan la Edad Media por su carácter más fúnebre e intolerante (Dakyns, 1973).

Muy distinta perspectiva de estos textos de la prensa adoptarán rigurosas novelas históricas como las de Rodrigo Amador de los Ríos. En su obra La leyenda del rey Bermejo, Rodrigo Amador presenta a un monarca de actuaciones dudosas pero de buen corazón. El jucio es así ambivalente: por un lado es cruel en su comportamiento con el rey árabe llamado el Ber-

\footnotetext{
${ }^{37}$ Pasando de nuevo al género de la conferencia, podemos ver cómo en el discurso ante la Real Academia de la Lengua que escribe en honor de Aparisi y Guijarro, Nocedal comenta: « $¡$ Ay del vencido, cuya historia traza la artera pluma del vencedor! Tal vez sea ésta la causa principal de la negra figura que hasta hace poco ostentaba en la historia, aunque no en la poesía, el desventurado príncipe D. Pedro de Castilla» (RAE, 1873, IV: 185)

${ }^{38}$ Su opinión más bien se conforma con lo que dice el autor de la crónica de Don Pedro Niño: "'El rey Don Pedro, dice, fué ome que usaba vivir mucho a su voluntad: mostraba ser muy justiciero; pero tanta era la su justicia e fecha de tal manera, que tornaba en crueldad'» (Trueba, 1863: 67). La Crónica de Pero Niño fue bastante popular en el siglo XIX, según deducimos de la frecuencia con que se la cita en la prensa ilustrada.

${ }^{39}$ En su relato anecdótico Vallejo demuestra que, a veces, por confusión, lo pudieron acusar de actos que en realidad no cometió (como la disecación del judío). Además, según Vallejo, la conducta de don Pedro es disculpable porque tuvo necesidad absoluta de matar para no ser muerto.

${ }^{40}$ Tras el asesinato de su hermano, don Pedro «se hace servir de comer; era como la bestia feroz husmeando aún la sangre de sus víctimas» (Márquez, 1887: 206).
} 
mejo (aunque los propios musulmanes se alegraran de su muerte) ${ }^{41}$ pero, por otro, don Pedro accede a no batir Antequera por la fuerza ${ }^{42}$. No obstante, independientemente de esta caracterización, lo que más se destaca en la novela es el intento del autor de imitar el lenguaje de los manuscritos notariales y de los cronistas árabes. Una atención al idioma y un propósito arqueológico que define la nueva estética de la novela histórica realista ${ }^{43}$.

Así, en la segunda mitad del XIX, cuando se busca que los argumentos se hagan más verosímiles, se persigue más que nunca en la novela tanto la ayuda de la Historia social como de la Lingüística, según demuestran escritores como Rodrigo Amador o Navarro Villoslada ${ }^{44}$. La novela se presenta desde el Naturalismo como el género más propicio para encontrar la deseada verdad, ésa que busca alcanzar la razón positivista. A este movimiento le precede el nuevo prestigio de la ciencia, especialmente de la Psicología, y con estos elementos culturales influyendo en la narrativa de ficción, no nos debe extrañar que en un relato de Pastor de la Rosa sobre don Pedro (incluso tan temprano como en 1863) se explique una aparición fantasmagórica como una «aberración sensitiva» de una conciencia «lastimosamente alterada» (Estruch, 1994: 11). El desarrollo de la Fisiología estimula a partir de entonces la intención de explicar los caracteres de los protagonistas.

Pero a pesar de estos intentos de verosimilitud realista, finalmente, buceando en las narraciones poéticas, novelísticas o dramáticas que se escriben sobre don Pedro ${ }^{45}$, se aprecia una contradicción de propósitos en

${ }^{41}$ Rodrigo Amador ofrece muchos datos en un texto donde se muestra extremadamente erudito. Justifica la decisión de don Pedro de matar al Bermejo por las prescripciones contenidas en las leyes de la Partida que los nassaríes adquirieron. Pero don Pedro falta a la hospitalidad, algo que no puede entender el Bermejo, pues ésta es sagrada, y considera que se le hace un arresto con alevosía cuando está comiendo.

${ }^{42}$ Como le pide el Sultán, para que no sea cierta la acusación de cruel que achacan al rey sus enemigos. Don Pedro contestará: «Harto me fatiga la fama de sanguinario que aquellos desventurados hijos de mi buen padre me achacan, cuando me veo forzado a castigar la felonía de mis súbditos, para que aquí se derrame más sangre de la que se ha derramado» (Amador de los Ríos, 1890: 338). También se muestra don Pedro compasivo al ver las quejas de Mohammad por su amada, a quien cree secuestrada por el Bermejo, ya que a él también le apenó la muerte de María Padilla (ibidem: 344).

${ }^{43}$ Es interesante, en este sentido, el momento en que, valiéndose del trujamán, don Pedro contesta en castellano antiguo a la demanda del Bermejo, palabras que serán traducidas al árabe por Idrís para que las comprenda el rey musulmán (Amador de los Ríos, 1890: 405).

${ }^{44}$ Navarro Villoslada tiene un especial cuidado con el lenguaje en su obra Amaya $o$ los vascos en el siglo VIII - publicada en 1879-, tanto para reproducir arcaísmos como términos de procedencia regional vasca (véase, por ejemplo, Navarro Villoslada, 1979: 147, 150, 200-221, 649).

${ }_{45}$ Para un buen recuento de éstas véase la bibliografía que Picoche (1980: 63-66) recoge en su introducción a Zorrilla. Sobre los dramas, es más completa y detallada la descripción que hace Lomba y Pedraza (1899: 264-274). 
unas historias que se debaten entre la erudición y el vuelo de la imaginación. Esto sin contar con que los escritores, como hemos visto, disponen del personaje en función de intereses tanto estéticos como políticos. El resultado se refleja en el uso equívoco del vocabulario o en el mismo dibujo del protagonista, tan pronto castellano auténtico como sensual imitador de los árabes (por ejemplo, en la teoría estética de Pedro de Madrazo [1872: $\left.43{ }^{46}\right)$. En el fondo, se percibe una misma psicología en la sociedad ochocentista, que se delata en tomas de posturas paralelas en la Literatura y en la Historia. Se defiende, por ejemplo, una noción semejante de la mujer, que se simboliza en esa Blanca de Borbón, enamorada y víctima, celosa de todas las amantes del rey en Men Rodríguez de Sanabria, de Fernández y González ${ }^{47}$.

En el recuento último, la Literatura, como la Historia, no logra ponerse de acuerdo en medio de 'su obsesión por la figura del Rey «Cruel». Parafraseando unos versos de Cano y Cueto (1875: 103-104), a don Pedro le darán «distintos nombres/ los que analizan sus hechos», en un «reñidísimo torneo» crítico que muestra cómo tras vivir «siempre en guerra», todavía mueve «a discordias, muerto».

\section{V}

Para recapitular lo que vamos diciendo, podemos señalar que existe una influencia mutua entre la Literatura y la Historia que se aprecia en múltiples detalles de las diferentes narraciones sobre don Pedro. Diremos entonces que la indefinición historiográfica del Romanticismo tiene una continuación clara en su heredero directo, el Realismo, que nunca abandonó los relatos de ficción histórica (aunque cuente el pasado de diferente forma, como en los Episodios Nacionales de Pérez Galdós). Esto explica que la tradición literaria pese sobre las narraciones historiográficas de la segunda mitad de siglo, que llevan a sus espaldas no sólo las leyendas del pasado sobre el personaje sino la fusión de géneros científicos y literarios de la época romántica.

Así, desde esta difícil delimitación, historiadores como Menéndez Pelayo (1944, I: 347) explicarán el carácter de don Pedro, curiosamente, a partir

${ }^{46}$ Para Madrazo, don Pedro intenta emular la suntuosidad de la Alhambra. Madrazo rechaza el auge de la arquitectura arábigo-española e identifica el arte mudéjar con lo opuesto a lo cristiano-castellano.

47 Véase este monólogo de la reina: «iDios te perdone, Pedro, lo infeliz que me haces! (...) ¡Matar al rey! ¿Y crees tú, traidor maestre, que yo consentiría en la muerte de mi esposo? ¡Ella, ella sí! ¡Que muera pues me lo roba! ¡Pero él, Dios mío! ¡Antes se destruyera el mundo entero! ¡Antes caigan la muerte y el infierno sobre mí! -y su llanto se hizo más profundo, más desagarrador» (Fernández y González, 1975a: 180). 
de una mirada cercana a la del Naturalismo, refiriéndose a «la insensata fiereza de su condición, su vesania congénita e incurable, sus alternativas de rigor y flaqueza». Y otros como Guichot y Mérimée harán uso del romance popular para explicar determinados pasajes de la historia del rey ${ }^{48}$.

En la novela, siguiendo la frecuente transcripción de textos medievales que realizan los libros y los artículos de Historia (publicados en la prensa ilustrada), se comienzan a copiar supuestos documentos inventados en los que el narrador realiza un esfuerzo lingüístico de imitación de la lengua del XIV muy lejana de aquella fabla a la que nos habían acostumbrado los textos áureos ${ }^{49}$. Ahí están las obras de Rodrigo Amador de los Ríos o incluso de Fernández y González, ya señaladas. El lenguaje antiguo se comienza a reproducir, así, dentro del texto, dentro de la posible familiarización que llevarían a cabo los trabajos eruditos de las revistas. Si Montoto en su historia sobre don Pedro introduce cartas medievales en medio de su relación, en un estadio posterior Rodrigo Amador mimetiza el habla de los siglos medios no como algo separado de la narración sino como parte integrante de la caracterización de los personajes, diferenciando, incluso dentro de su diálogo, entre cristianos y árabes (la fraseología de estos últimos se emula a lo largo del relato, que toma el punto de vista de un cronista musulmán). Así pues, esta más ajustada reproducción del lenguaje medieval entrará en el cuerpo del texto de ficción debido a una estética arqueológica realista (en un momento en que se realizan abundantes falsificaciones de textos medievales) que rechaza la irrealidad de la fabla $^{50}$.

Por otro lado, ya hemos visto cómo la condición de las narraciones de la prensa sobre don Pedro oscila entre lo historiográfico y lo literario, por ejemplo la anécdota de Pedro el Cruel que publica el Museo de Familias ${ }^{51}$. Los argumentos de la Historia se usan para justificar la puesta a punto de la narración y defender a los personajes, pero éstos pueden mezclarse incluso con otros inventados. Además, la pseudo-Psicología y el vocabulario político no dejan de aparecer en una interrelación que difumina las fronteras. La Historia no desea abandonar el melodrama ni, formalmente, el desarrollo narrativo, bajo la influencia del realismo novelístico-burgués del Ochocientos (Barthes, 1984: 165). Y la novela histórica no renunciará a la

\footnotetext{
${ }^{48}$ Para Guichot, véase la nota 17. Por su parte, Mérimée reproduce en su apéndice los romances de la muerte de don Fadrique y doña Blanca.

${ }^{49}$ Y que criticará duramente Valera (1909, t. XXV: 34$)$ : «la mayor parte de los que han compuesto en el día versos o prosa en fabla antigua, recelo mucho que han fablado una fabla que nunca se fabló, ni en lo antiguo, ni en lo moderno».

so Pérez Galdós (1992: 62) se burlará, en su prólogo a El sabor de la tierruca de Pereda, de la artificialidad y la retórica de la fabla, pues, según él, resultan infranqueables las diferencias entre la manera de escribir y la de hablar.

51 Véase el relato que presenta un Anónimo (1861) donde se demuestra que el hebreo que intenta disecar don Pedro era en realidad un perro muerto.
} 
ilusión de veracidad hasta el final, cuando, con la llegada del Modernismo, se ciña únicamente a su vocación formalista ${ }^{52}$.

No obstante, esto no me hace olvidar el evidente esfuerzo que la historiografía de la segunda mitad de siglo realizó para distanciarse de la fácil fusión de su discurso con lo literario. La edición de la obra de Ferrer del Río se presenta de una manera mucho más austera que su precedente, la de Montoto, donde la apariencia novelada se expresaba a través de numerosos dibujos que adornaban la narración. Sin duda, la Academia de Historia quería un aspecto de mayor seriedad y entonces la representación plástica de don Pedro se relega al terreno de la pintura, que le reinventa en numerosas ocasiones. Pero ya a finales de la centuria, una nueva estética no dejará de afectar a los libros de historia, y el de Guichot hace gala de una presentación física semejante a la de las publicaciones premodernistas referidas al Medievo, en una voluntaria remembranza de los manuscritos de los tiempos pasados. Un tipo de portada de la que presume también la reedición en 1886 de la novela histórica La campana de Huesca, publicada por Cánovas del Castillo en $1852^{53}$.

Historia y Literatura se aúnan incluso en otras empresas consideradas por entonces más altas: en medio de una historiografía que ensalza los valores del pasado, y en un momento en que abunda la regional, Sevilla busca, a través de su cronista oficial Guichot o de su Revista de Ciencias, Literatura y Artes, reclamar su importancia en la narración de don Pedro. Los poemas de Cano y Cueto harán otro tanto en el terreno literario.

En este campo, críticos como Orlando pedirán repetidas veces más rigor y realismo a los relatos de ficción, al igual que hará Menéndez Pelayo con la poesía o el drama ${ }^{54}$. En 1884, Orlando (1884: 274-275) critica la vaguedad histórica de unas narraciones llenas de estereotipos, «que lo mis-

\footnotetext{
${ }^{52}$ Para una reflexión sobre la problemática condición de la novela histórica en el XIX (por su mezcla de ficción e historia) véase el famoso trabajo de Amado Alonso (1942), así como las conclusiones que presento en mi libro citado.

${ }^{53}$ En la Biblioteca Widener de Harvard tuve la oportunidad de consultar esta magnífica reedición, una publicación muy cuidada, con iniciales góticas al comienzo de cada capítulo. Clarín (1966: 1299-1304) comenta la salida de este elegante tomo, con portada a dos tintas por el impresor de la Real Casa M. G. Hernández, criticando duramente la obra. La mirada conservadora de Cánovas hacia el Medievo no era de su particular gusto.

${ }^{54}$ Menéndez Pelayo acusa a Almeyda Garret, en sus Notas a los poemas de Valera, de «falta de rigor y de severidad científica» (Valera, 1908, t. XVIII: 300) y alaba un drama de Núñez de Arce porque «a mayor grado de exactitud histórica, corresponde también mayor grado de evidencia poética» (Menéndez Pelayo, 1883: 312-313). Asimismo Luis Pidal y Mon, en su discurso de ingreso en la RAE de 1895, reclama que el drama de época se compenetre con la verdad histórica y que no se desfiguren los sucesos (Cabrales Arteaga, 1985: 287). De todos modos, estas reclamaciones se remontan al siglo XVII, pues el Conde de la Roca, en su monografía sobre don Pedro, recomienda a los autores de dramas y leyendas que se cuiden de no falsear los personajes históricos.
} 
mo pudieran pertenecer a la época de Carlos IV [...] que a los tiempos de Don Pedro el Cruel o de Don Rodrigo».

Pero si se pretende que la Literatura se acerque a la Historia, aunque sea vía el ideal del esteticismo vigente, esto no podía más que producir confusiones en ambos bandos. $Y$ en este sentido, recordamos algunos razonamientos del historiador Tubino (1887: 3-6), que establece una dialéctica entre Romanticismo y Clasicismo personificándolos en los sistemas español y francés, respectivamente. El Romanticismo medieval y castellano que ejemplifica don Pedro se opone para él al Renacimiento que defienden Francia y el Papa ${ }^{55}$. Como vemos, en el fondo se trata de una cuestión de prestigio del vocabulario, y lo que se deduce de todo esto es que todavía cuando Tubino escribe, en 1887, la Literatura y la Historia aún debaten sus fronteras y los valores políticos y estéticos que se atribuyen a don Pedro (Castilla, el Romanticismo) continúan con vigencia.

Para finalizar, y como conclusión de lo expuesto, se puede decir que lo más revelador del estudio de las narraciones sobre don Pedro, en los ámbitos de la Literatura y de la Historia, es descubrir cómo las fronteras entre estas actividades se presentan difuminadas, y cómo la posición que adopta cada escritor en la llamada discordia está estrechamente relacionada con una serie de condicionantes previos. El imaginario del monarca, como el medieval en tantas ocasiones, se utiliza como arma arrojadiza de la opinión política, además de prestarse a una fácil y atractiva recreación estética, por la complejidad de un ambiguo carácter y por estar rodeada de un halo de leyendas.

Novelas como las de Manuel Fernández y González fomentarán en la segunda mitad de siglo una continua recreación de este tipo de mitos medievalistas, en las que no se deja de establecer una nostálgica diferencia entre el ayer y el hoy ${ }^{56}$. Los personajes del Medievo serán manipulados por la Literatura y la Historia para hacerlos concertar con unas ideas políticas.

A pesar de esto, bajo la influencia de la estética realista, de la Psicología y la Fisiología, se intenta comprender el carácter de don Pedro y

${ }^{55} \mathrm{El}$ enfrentamiento de un personaje histórico, que supuestamente representa a Castilla, contra Francia y el Papa también se da en las Mocedades de Rodrigo, como recuerda Gómez Moreno (2002: 336).

56 Véanse, por ejemplo, en la novela Don Ramiro de Aragón, del año 1858, las palabras de Manuel Fernández y González (1975b: 8): «Imposible sería encontrar un punto de comparación entre aquella civilización, si civilización podía llamarse, y la presente $[\ldots] »$. 
acercarlo a la contemporaneidad: en este análisis se mostró el reverso del proceso de magnificación mitológica que llevó a cabo el Romanticismo. Don Pedro apareció en ocasiones como la víctima de sus propias debilidades fisiológicas, muy en la línea del determinismo naturalista.

Sea como sea, y desde estas múltiples perspectivas, la narración sobre el rey se convierte a lo largo de toda una centuria en un bello ejemplo de esa implicación en la Historia, única y apasionada, que se dio en el XIX. La segunda mitad de siglo se lanza a una exploración de este personaje revelando en el camino algunas contradicciones y debilidades, sin llegar a conclusiones finales, pero sí a un método de autorreflexión. Esta época descubre, por ejemplo, las fisuras que existen en el ideal de escritura historiográfico y en el del género literario de la novela histórica, además de su propia y profunda división ideológica. También el placer estético (y parnasiano) en la reivindicación de la barbarie y la crueldad, en la antesala del Modernismo. Además, muestra con claridad cómo a través del lenguaje (tanto por los silencios como por los términos escogidos) unos mismos hechos se construyen en elementos que verifican conclusiones diferentes.

De este modo, a través de un controvertido vocabulario, el imaginario de don Pedro nos habla más del siglo XIX que de la Edad Media, más de la concepción estética y científica de la Literatura y la Historia que de la existencia cotidiana o bélica del siglo XIV. El pensamiento sobre Castilla, la monarquía, la crueldad o la mujer se canaliza en relaciones interminables. En todas estas discusiones, en las que los textos dialogan dialécticamente unos con otros, remontándose a la escritura de López de Ayala, Pedro I vive como un largo personaje textual. Evocado en los documentos de su época y en interpretaciones de fuentes intermedias, habita en una extensa cadena de relecturas. Al final, el Rey «Cruel» sigue escapando a la definición.

\section{BIBLIOGRAFÍA CITADA}

AMADOR DE LOS Ríos, Rodrigo (1890), La Leyenda del Rey Bermejo, ilustración de Isidro Gil, Barcelona, Daniel Cortezo y C. ${ }^{a}$ - Editores (Biblioteca «Arte y Letras»).

Alonso, Amado (1942), Ensayo sobre la novela histórica. El Modernismo en «La gloria de Don Ramiro», Buenos Aires, Facultad de Filosofía y Letras de la Universidad de Buenos Aires.

Anónimo (1861), «Anécdota del tiempo de D. Pedro el Cruel», Museo de las Familias, 24, pp. 189-190.

B. (1889), «El movimiento intelectual en España», Revista de España, CXXV (enero y febrero), pp. 195-202.

BARTHES, Roland (1984), 'De l'histoire au réel', en Le bruissement de la langue: essais critiques IV, París, Éditions du Seuil, pp. 153-174.

Boos, Florence S., ed. (1992), History and Community. Essays in Victorian Medievalism, Nueva York/ Londres, Garland Publishing, Inc. 
CABrales Arteaga, José Manuel (1985), «Notas sobre la Edad Media en el teatro español entre 1870 y 1900», Boletín de la Biblioteca de Menéndez Pelayo, LXI, pp. 285-313.

- (1986), La Edad Media en el Teatro Español, entre 1875 y 1936, Madrid, Fundación Juan March.

CAMPOAMOR, Ramón de (1853), Colón. Poema por don Ramón de Campoamor, Valencia, Imprenta de J. Ferrer de Orga.

CANo y Cueto, Manuel (1875), Leyendas y tradiciones de Sevilla, Sevilla, Francisco Álvarez y $\mathrm{C}^{\mathrm{a}}$, editores.

CÁNOVAS DEL CASTILlo, Antonio (1981), Obras completas, pról. Manuel Fraga Iribarne, estudio preliminar de Juan Antonio Cánovas del Castillo, intr. Carmen Llorca, Madrid, Fundación Cánovas del Castillo, t. I.

CARRASCo URgoiti, María Soledad (1956), El moro de Granada en la literatura (del Siglo XV al XX), Madrid, Revista de Occidente.

CASTElar, Emilio (1885), El suspiro del moro, Madrid, Imprenta de Fortanet, t. 1.

Cirujano Marín, Paloma, Teresa Elorriaga Planes y Juan Sisinio Pérez Garzón (1985), Historiografía y nacionalismo español (1834-1868), Madrid, CSIC.

Clarín, Leopoldo Alas (1966), Obras selectás de Leopoldo Alas "Clarín», segunda edición, Madrid, Biblioteca Nueva.

DAKYNS, Janine R. (1973), The Middle Ages in French Literature. 1851-1900, Londres, Oxford University Press.

ESPRONCEDA, José de (1954), «Blanca de Borbón» (1870), en Obras completas, edición, prólogo y notas de Jorge Campos, Madrid, Atlas, pp. 257-292 (Biblioteca de Autores Españoles, LXXII).

ESTRUCH, Joan (1994), «Prólogo», en Leyendas, edición, prólogo y notas de Joan Estruch, estudio preliminar de Russell P. Sebold, Barcelona, Crítica, pp. 3-38.

FaIRLIE, Alison (1947), Leconte de Lisle's Poems on the Barbarian Races, Cambridge, Cambridge University Press.

FERNÁNDEZ ESPINO, José (1860), «Apuntes sobre el carácter y conducta del Rey D. Pedro, con motivo de la carta inédita que publicamos a continuación, sobre el castigo que impuso a D. Alonso Fernández Coronel, debida a nuestro amigo el estimable escritor D. José Velázquez y Sánchez, archivero del Excmo. Ayuntamiento de esta ciudad», Revista de Ciencias, Literatura y Artes, pp. 140-152.

FERNÁNDEZ y GONZÁLEZ, Manuel (1930), El condestable don Álvaro de Luna (1851), Madrid, Editorial Pueyo, t. II.

- (1975a), Men Rodríguez de Sanabria (1853), Madrid, Tebas.

- (1975b), Don Ramiro de Aragón (1858), Madrid, Tebas.

FERRER DEL Río, Antonio (1851), Examen histórico-crítico del reinado de Don Pedro de Castilla. Obra premiada por voto unánime de la Real Academia Española en el certamen que abrió la misma en 2 de Marzo de 1850, Madrid, Imprenta Nacional.

FuensANTA DEL VALLE, El Marqués de la (1874), «Instituciones de Venecia. El Consejo de los Diez», Parte Literaria Ilustrada de El Correo de Ultramar, 1119, p. 14.

GómEZ MORENO, Ángel (2002), «La poética del Romancero y la materia cidiana», en Carlos Alvar, Fernando Gómez Redondo y Georges Martin, eds., El Cid: de la materia épica a las crónicas caballerescas, Alcalá de Henares, Servicio de Publicaciones de la Universidad de Alcalá, pp. 325-338.

Guichot, Joaquín (1878), Don Pedro Primero de Castilla. Ensayo de vindicación crítico-histórica de su Reinado, Sevilla, Imp. de Gironés y Orduña.

HARTZENBUSCH, Juan Eugenio (1852), «Isabel y Gonzalo. Leyenda», en Cuentos varios, Madrid, Imprenta a cargo de C. González, pp. 91-107.

Jove, José G., y LUNA, F. (1869), «Estudios históricos. Reflexiones sobre el reinado de Don Pedro I de Castilla», Parte Literaria Ilustrada de El Correo de Ultramar, 874, pp. $242-244 ; 875$, pp. 258-259; 876, pp. 281-282. 
LAFUENTE, Modesto (1852), Historia general de España, desde los tiempos más remotos hasta nuestros días, Madrid, Establecimiento tipológico de Mellado, t. VII.

LOMBA Y PedRaZA, José R. (1899), «El Rey D. Pedro en el teatro», en Homenaje a Menéndez y Pelayo en el año vigésimo de su profesorado: Estudios de erudición española con un prólogo de D. Juan Valera, Madrid, Librería General de Victoriano Suárez, t. II, pp. 257-339.

LóPez DE Ayala, Pero (1953), «Crónica del Rey Don Pedro», con las enmiendas de Jerónimo Zurita, y las correcciones y notas añadidas de Eugenio de Llaguno y Amirola, en Crónicas de los Reyes de Castilla, colección ordenada por Cayetano Rosell, t. I, Madrid, Atlas, pp. 393-614 (BAE, t. LXVI).

Madrazo, Pedro (1872), Discurso del Excmo. Sr. Don Pedro de Madrazo, en contestación al anterior [El estilo mudéjar en arquitectura. Discurso de Excmo. Sr. Don José Amador de los Ríos, leído en la Junta Pública de 19 de junio de 1859]. Madrid: Imprenta de Manuel Tello, pp. 41-73.

MÁRQUEZ, Antonio J. (1887), «La desposada del rey./ Fantasía», La Ilustración Ibérica, 221 (26 de marzo), pp. 202-203 \& 206.

MenÉNDEZ PELAYo, Marcelino (1883), «Don Gáspar Núñez de Arce», en Autores dramáticos contemporáneos y joyas del teatro español del siglo XIX (1881-1882), única edición, Madrid, Imprenta de Fortanet, t. II, pp. 293-317.

- (1944), Antología de poetas líricos catellanos, ed. Enrique Sánchez Reyes, Santander, Aldus, 1944.

MÉRIMÉE, Prosper (1865), Histoire de Don Pèdre I Ir, Roi de Castille, París, Charpentier, Libraire-Éditeur, novena edición.

Montoto, José M. (1847), Historia del reinado de D. Pedro Primero de Castilla, llamado el Cruel, $2^{\mathrm{a}}$ ed., Sevilla, Imprenta de D. Carlos Santigosa, editor.

MORENO AlONSO, Manuel (1979), Historiografía romántica española. Introducción al estudio de la historia en el siglo XIX, Sevilla, Universidad de Sevilla.

NAVARro VillosladA, Francisco (1979), Amaya o los vascos en el siglo VIII (1879), Madrid, Tebas.

Nombela, Julio (1872), «Revista española», Parte Literaria Ilustrada de El Correo de Ultramar, 1007, pp. 290-291

ORLANDO (1884), «Novelas españolas del año literario», Revista de España, C (septiembre y octubre), pp. 265-280.

Palacio, Eduardo de (1888), «Un muchacho poeta», La Ilustración Artística, 323 (5 de marzo), p. 87.

PÉREZ Galdós, Benito (1992), «Prólogo. José María de Pereda», en El sabor de la tierruca. Obras completas de José María de Pereda. Tomo V, edición dirigida por Anthony H. Clarke y José Manuel GonZÁlez HerRán, Santander, Ediciones Tantín, pp. 59-66.

PICOCHE, Jean-Luis (1980), «Introducción», en José Zorrilla, El Zapatero y el Rey: Primera y Segunda partes, edición, introducción y notas de J.-L. Picoche, Madrid, Castalia, pp. 7-66 (Clásicos Castalia, 85).

Ramírez DE ARellano, Carlos (1860a), «D. Alonso Coronel y el castillo de Aguilar», Revista de Ciencias, Literatura y Artes, pp. 79-83.

- (1860b), «El castillo de Aguilar. Romance histórico», Revista de Ciencias, Literatura y Artes, pp. 84-90.

Real ACAdEMia Española (1873), Memorias de la Academia Española, Madrid, Imprenta y Esteriotipia de M. de Rivadeneyra, t. IV.

- (1886), Memorias de la RAE, Madrid, Imprenta y Fundición de Manuel Tello, impresor de cámara de S. M., t. V.

Retes, Francisco Luis de, y Francisco Pérez Echevarría (1872), Doña María Coronel: drama en tres actos y en verso, Madrid, Imprenta de Gabriel Alhambra. 
SAAvedra, Ángel de, Duque de Rivas (1841), Romances históricos, París, Librería de D. Vicente Salva.

SÁNCHEZ, Ángel (1994), La imagen del Rey don Pedro en la literatura del Renacimiento y del Barroco, Guadalajara, Aache Editores.

SANMARTín BASTIDA, Rebeca, Imágenes de la Edad Media: La mirada del Realismo, pról. Ángel Gómez Moreno, Madrid, CSIC (Anejos de Revista de Literatura, 56), 2002.

TruebA, Antonio de (1863), «La tragedia del infante», Parte Literaria Ilustrada de El Correo de Ultramar, 551, pp. 66-67.

Tubino, Francisco M. (1887), Pedro de Castilla. La leyenda de Doña María Coronel y la muerte de Don Fadrique, Sevilla, Imprenta de «La Andalucía».

VALERA, Juan (1905-1913), Obras completas, 34 ts., Madrid, Imprenta alemana.

VAllejo, José Mariano (1886), «Ruzafa. Tradición del tiempo de D. Pedro I de Castilla», La Ilustración Ibérica, 163 (13 febrero), pp. 106-107 \& 110.

VIDART, Luis (1890), «El Duque de Rivas. Apuntes bibliográficos», Almanaque para la Ilustración Española y Americana, pp. 10-24.

WHITE, Hayden (1992), El contenido de la forma: Narrativa, discurso y representación histórica, Barcelona/ Buenos Aires/ México, Ediciones Paidos.

ZAMORA Y CABALlERO, E. (1873), Historia general de España y de sus posesiones de Ultramar desde los tiempos primitivos hasta el advenimiento de la República, Madrid, Imprenta de José A. Muñoz y Compañía, t. II.

Zorrilla, José (1905), Obras completas. T. III: Dramas, Madrid, Manuel P. Delgado, Editor.

- (1917), Obras completas. T. I: Poesías, Madrid: Manuel P. Delgado, Editor. 


\section{RESUMEN}

Un viaje por el mito del Rey «Cruel»: la Literatura y la Historia después del Romanticismo, de Rebeca Sanmartín Bastida.

Este trabajo explora las diferentes maneras de enfrentarse a la figura de don Pedro que revelan la Historia y la Literatura, cada una desde sus propias aspiraciones. Después del Romanticismo, ambos ámbitos continuaron entrelazados a través de presupuestos comunes y contradicciones implícitas. El monarca «Cruel» se convierte en un importante catalizador de las pasiones de los escritores, y el análisis de los relatos que se tejen en torno a su figura descubre las influencias mutuas que la vocación de ficción literaria y de estudio histórico del pasado vivieron en aquellos momentos. Al final, no se alcanza un juicio unánime sobre don Pedro en este largo diálogo intertextual, pero la propia necesidad de esta narración nos invita a reflexionar en torno a las aspiraciones y carencias, volcadas en estos relatos, del pensamiento ochocentista.

Palabras clave: Historia de la Literatura. Comparatismo. Teoría de la Historia. Siglo XIX. Medievalismo. Pedro I «el Cruel».

\section{SUMMARY}

This work deals with the different ways of confronting Don Pedro's character after Romanticism, which reveal the contradictions and common presuppositions that Literature and History still shared. The monarch «Cruel» became, in a series of narratives, the catalyst for the writers' passions, and the analysis of the various tales created around his figure shows the mutual influence between literary fiction and historical studies at that time. In the end, no universal agreement was reached in the long intertextual dialogue, but the very necessity of this narrative invites us to reflect on all the aspirations and limitations betrayed in the 19th Century thought in these stories.

Key wods: History of Literature. Comparativism. Theory of History. Nineteenth Century. Medievalism. Peter the First «the Cruel». 